\title{
Occupational Stress and Quality of Life in Mental Health Welfare Center Workers
}

\author{
Woo-Jeong Kim, MD ${ }^{1,2}$, Kwang-Hun Lee, MD, PhD ${ }^{3}$, Bo-Hyun Yoon, MD, PhD ${ }^{4}$, \\ Jong-Hun Lee, MD, PhD ${ }^{5}$, Moon-Doo Kim, MD, PhD ${ }^{6}$, Young-Eun Jung, MD, PhD ${ }^{6}$, \\ Min-Jung Soh, $\mathrm{MD}^{2}$, Sang-Yeol Lee, MD, $\mathrm{PhD}^{2}$
}

${ }^{1}$ Departments of Psychiatry, Wonkwang University Hospital, ${ }^{2}$ Department of Psychiatry, Wonkwang University School of Medicine, Iksan, ${ }^{3}$ Department of Psychiatry, Dongguk University College of Medicine, Gyeongju, ${ }^{4}$ Department of Psychiatry, Naju National Hospital, Naju, ${ }^{5}$ Department of Psychiatry, Daegu Catholic University School of Medicine, Daegu, ${ }^{6}$ Department of Psychiatry, Jeju National University School of Medicine, Jeju, Korea

Background: This study aimed to examine the occupational stress and quality of life of mental health welfare center workers and to identify the impact of occupational stress on compassion satisfaction, burnout, and secondary traumatic stress.

Methods: This study included 588 employees working at 15 provincial/municipal/regional mental health welfare centers. Demographic and psychosocial factors were surveyed. Data were analyzed using independent t-test, Pearson's correlation test, and multiple regression analysis.

Results: The high-risk group for occupational stress showed low compassion satisfaction, high burnout, and high secondary traumatic stress. Compassion satisfaction showed a significant negative correlation with occupational stress. Burnout and secondary traumatic stress showed a significant positive correlation with occupational stress. Occupational stress factors affecting compassion satisfaction included lack of reward $(\beta=-0.155, p<0.001)$, whereas those affecting burnout included physical environment $(\beta=0.028, p<0.01)$, job demand $(\beta=0.042, p<0.001)$, relationship conflict $(\beta=0.033, p<0.01)$, job instability $(\beta=0.016, p<0.01)$, lack of reward $(\beta=0.051, p<0.001)$, and occupational climate $(\beta=0.024, p<0.01)$. Additionally, occupational stress factors affecting secondary traumatic stress included physical environment $(\beta=0.063, p<0.001)$ and job instability $(\beta=0.020, p<0.05)$.

Conclusion: Occupational stress had a significant impact on compassion satisfaction, burnout, and secondary traumatic stress. Therefore, active interventions against occupational stress factors are necessary to improve the quality of life of mental health welfare center workers.

Keywords Community mental health services; Occupational stress; Job satisfaction; Burnout; Compassion fatigue

\section{INTRODUCTION}

A mental health welfare center is a public mental health promotion agency dedicated to providing integrated and ongoing services for the mental health problems in a community. Mental health welfare center workers include psychiatrists, mental health nurses, mental health social workers, and mental health clinical psychologists. The mental health welfare center workers in Korea are continuously exposed to stress factors such as job conflicts due to various occupational groups, 24hour shifts, irregular working conditions, employment insecurity, low wages, and heavy workload [1]. Such occupational stress affects health-related quality of life and the degradation of quality of life can lead to reduced job efficiency as well as to various psychosocial problems

Received February 17, 2020, Revised February 24, 2020, Accepted February 25, 2020

Correspondence: Sang-Yeol Lee, MD, PhD

Department of Psychiatry, Wonkwang University Hospital, 895 Muwang-ro, Iksan 54538, Korea

TEL +82-63-859-1044 FAX +82-63-857-1043 E-mail psysangyeol@hanmail.net ORCID https://orcid.org/0000-0003-1828-9992

Copyright $@$ by Korean Society for Affective Disorders. All Rights reserved.

This is an Open Access article distributed under the terms of the Creative Commons Attribution Non-Commercial License (http://creativecommons.org/licenses/ by-nc/4.0/) which permits unrestricted non-commercial use, distribution, and reproduction in any medium, provided the original work is properly cited. 
such as depression, posttraumatic stress disorder, and substance abuse [2].

Occupational stress refers to the physical or psychological reaction of an organization's members to the working environment at the workplace, that occurs when the individual's skills and abilities are incompatible with the individual requirements provided by the regulations and environment of the job. It is closely related to negative environmental factors such as work overload, ambiguity in role, role conflict and poor working conditions [3].

Quality of life refers to the "perception of the place of life felt in relation to an individual's goals, expectations, standards and interests within the cultural background in which the individual lives", and the concept of "professional quality of life" has been proposed as jobrelated quality of life that is directly related to the characteristics of and performance at work [4]. Mental health welfare center workers are often in contact with subjects who have experienced traumatic events, and may experience secondary traumatic stress or burnout due to the work itself, while experiencing satisfaction in the process of helping others. Negative experiences such as secondary traumatic stress and burnout have been referred to as compassion fatigue while the positive experience of satisfaction has been named compassion satisfaction, and the experiences have been studied in professionals in various fields [5].

The compassion satisfaction experienced by mental health welfare center workers is affected by the positive emotions that a mental health service provider can feel in helping others, the satisfaction they find in a job, the degree to which they feel successful in their job, and the level of support they receive from their work colleagues [6]. The feelings of compassion manifested by caring for the patient also lead to positive emotions, which act as a protective factor for compassion fatigue, and the satisfaction of being a positive agent in the process of helping others reduces compassion fatigue and burnout [7].

Compassion fatigue refers to the negative phenomena experienced during professional assistance activities for trauma survivors, and an increase in compassion fatigue results in negative physical and mental impact [8]. According to Stamm [9], compassion fatigue embodies secondary traumatic stress and burnout. Secondary traumatic stress is a concept describing the experience of PTSD-like reactions such as invasive thinking of the survivors who experienced traumatic events, imagination, difficulty sleeping, and the avoidance of situations related to the event [10]. This phenomenon occurs as a response when the memory is triggered by a stimulus that can be associated with the event after detailed information about the client's traumatic event is stored as a fear memory by the mental health worker. Burnout is a superordinate concept that includes three subdomains: exhaustion, depersonalization, and a sense of deterioration [11]. Burnout is associated with work-related stress, such as excessive workload, inefficient organization, and unsupportive work environment, and with the overall difficulty and helplessness of performing a job effectively. According to Rothmann [12], the higher the occupational stress, the greater the burnout.

In the course of their work, mental health welfare center workers are subject to verbal harassment, sexual harassment, and physical assault from service recipients due to the nature of the work. As a result, regardless of proficiency at work, the longer the working period, the more prone to emotional burnout they get. However, the study of occupational stress factors affecting their compassion satisfaction, burnout, and secondary traumatic stress is insufficient. To date, previous studies have been limited to social workers [13], nurses [14], and occupational therapists [15] and are limited to surveys of damage and violent experiences occurring at their work sites. Therefore, the purpose of this study is to 1) investigate the overall condition of occupational stress and quality of life subfactors including compassion satisfaction, burnout, and secondary traumatic stress in mental health welfare center workers, 2) identify the impact of occupational stress on the quality of life in mental health welfare center workers, and 3) provide suggestions and policy directions for improving the quality of life.

\section{MATERIALS AND METHODS}

\section{Subjects and questionnaires}

This study was conducted between April 2019 and October 2019 with 613 subjects who included employees at $15 \mathrm{provincial} / \mathrm{municipal} / \mathrm{regional}$ mental health welfare centers and addiction management centers (mental health nurses, mental health social workers, mental health clinical psychologists, etc.) and part-time psychiatrists. The final analysis included 588 subjects, after excluding 25 subjects who were considered unresponsive or gave inadequate responses. The demographic and 
psychosocial factors of subjects were collected using self-administered questionnaires and analyzed. After conducting a briefing session with subjects to explain the purpose of the study, informed consent forms were obtained. This study was approved by the Institutional Review Board (IRB No. WKUH 2019-09-004) of the Wonkwang University Hospital.

\section{Measurement tools}

\section{1) Occupational stress}

Occupational stress was measured using the Korean Occupational Stress Scale (KOSS-26) developed by the Korea Institute of Occupational Safety and Health. KOSS-26 is a scale with two physical environment questions added to the short version of the occupational stress scale with 24 questions, and consists of eight subsections, i.e. physical environment, job demand, degree of autonomy, relationship conflict, job instability, organizational system, lack of reward, and occupational climate. Each question is scored on a scale of 1 to 4 points and a high score indicates high occupational stress [16]. To compare the level of quality of life subfactors according to occupational stress, those with the highest quartile of KOSS-26 score were categorized as occupational stress high-risk group while the rest of the subjects were categorized as occupational stress low risk group for analysis [17]. According to the criteria for occupational stress high risk group, the total score for occupational stress is calculated by dividing the sum of the converted scores of the eight areas by eight after calculating (actual scorenumber of questions) $\times 100 /($ expected maximum scorenumber of questions), according to the development and standardization of the occupational stress measurement tool for Koreans [16].

\section{2) Quality of life}

To measure quality of life, we used Professional Quality of Life Scale 5 (ProQOL 5), a useful tool for assessing the overall quality of life of professionals following indirect trauma exposure [9]. ProQOL 5 was developed by Stamm [9] and consists of three subareas: compassion satisfaction, burnout and secondary traumatic stress. Each subarea is measured by 10 questions which are scored on a scale of 1 to 5 where 1 indicates 'not at all' and 5 indicates 'very much so.' A high score indicates high compassion satisfaction, burnout and secondary traumatic stress. This study used the Korean Profes- sional Quality of Life Scale 5 translated by Joo et al. [18].

\section{Statistical analysis}

To compare the differences in quality of life according to the subject's occupational stress, an independent t-test was conducted and Pearson's correlation test was carried

Table 1. Demographic characteristics of participants

\begin{tabular}{|c|c|}
\hline Variable & Value $(n=588)$ \\
\hline \multicolumn{2}{|l|}{ Province } \\
\hline Jeollabukdo & $141(24.0)$ \\
\hline Jeju & $44(7.5)$ \\
\hline Jeollanamdo & $119(20.2)$ \\
\hline Gyungsangbukdo & $183(31.1)$ \\
\hline Daegu & $101(17.2)$ \\
\hline Age & $35.24 \pm 8.26$ \\
\hline \multicolumn{2}{|l|}{ Sex } \\
\hline Male & $149(25.3)$ \\
\hline Female & $439(74.7)$ \\
\hline \multicolumn{2}{|l|}{ Marital status } \\
\hline Married & $322(54.8)$ \\
\hline Unmarried & $253(43.0)$ \\
\hline Divorced & $10(1.7)$ \\
\hline Others & $3(0.5)$ \\
\hline \multicolumn{2}{|l|}{ Religion } \\
\hline Protestant & $161(27.4)$ \\
\hline Catholic & $67(11.4)$ \\
\hline Buddhism & $54(9.2)$ \\
\hline Won Buddhism & $5(0.9)$ \\
\hline No religion & $301(51.2)$ \\
\hline \multicolumn{2}{|l|}{ Type of employment } \\
\hline Regular & $246(41.8)$ \\
\hline Part time & $342(58.2)$ \\
\hline \multicolumn{2}{|l|}{ Type of work } \\
\hline Severe mental illness management & $187(31.8)$ \\
\hline Mental health promotion project & $144(24.5)$ \\
\hline Children $\&$ adolescents project & $50(8.5)$ \\
\hline Suicide prevention project & $178(30.3)$ \\
\hline Addiction management project & $29(4.9)$ \\
\hline \multicolumn{2}{|l|}{ Type of occupation } \\
\hline Mental health nurse & $105(17.9)$ \\
\hline Mental health clinical psychologist & $40(6.8)$ \\
\hline Mental health social worker & $181(30.8)$ \\
\hline Nurse & $99(16.8)$ \\
\hline Clinical psychologist & $14(2.4)$ \\
\hline Social worker & $124(21.1)$ \\
\hline Others & $25(4.3)$ \\
\hline
\end{tabular}

Values are presented as number (\%) or mean \pm standard deviation. 
out to examine the correlation between occupational stress and quality of life. Also, in order to examine the factors that affect the subareas of quality of life (compassion satisfaction, burnout, and secondary traumatic stress), multiple regression analysis was carried out. Collected data were analyzed using IBM SPSS Statistics for Windows, Version 21.0 (IBM Co., Armonk, NY, USA) and the results were considered significant in case $\mathrm{p}<0.05$.

\section{RESULTS}

\section{Demographic characteristics of subjects}

For demographic characteristics i.e. sex, marital status and religion, the highest percentages were for female $(\mathrm{n}=439,74.7 \%)$, married $(\mathrm{n}=322,54.8 \%)$, and atheists $(\mathrm{n}=301,51.2 \%)$, respectively. Among occupational characteristics the highest percentages were for part-time work ( $\mathrm{n}=342,58.2 \%)$, and mental disease management $(\mathrm{n}=187,31.8 \%)$, followed by mental health social workers $(\mathrm{n}=181,30.8 \%)$ (Table 1).

\section{Differences in professional quality of lifedepending on occupational stress}

As for professional quality of life, the high-risk stress group had low compassion satisfaction $(\mathrm{t}=-5.888$, $\mathrm{p}<0.001)$, and high burnout $(\mathrm{t}=8.422, \mathrm{p}<0.001)$ as well as high secondary traumatic stress $(\mathrm{t}=3.853, \mathrm{p}<0.001)$ compared to the low risk stress group (Table 2).

\section{Correlation between occupational stress and professional quality of life}

Among the subareas of quality of life, compassion satisfaction showed negative correlation with occupational stress factors including physical environment $(\mathrm{r}=-0.188$, $\mathrm{p}<0.01)$, job demand $(\mathrm{r}=-0.171, \mathrm{p}<0.01)$, the lack of

Table 2. Differences of compassion satisfaction, burnout and secondary traumatic stress between occupational stress high risk group and low risk group

\begin{tabular}{lcrrr}
\hline \multirow{2}{*}{ Variable } & \multicolumn{2}{c}{ Occupational stress } & t & p-value \\
\cline { 2 - 3 } & High risk group $(n=91)$ & Low risk group $(n=497)$ & & \\
\hline Compassion satisfaction & $28.75 \pm 6.21$ & $32.75 \pm 5.92$ & -5.888 & $<0.001$ \\
Burnout & $28.73 \pm 3.90$ & $25.01 \pm 3.87$ & 8.422 & $<0.001$ \\
\hline Secondary traumatic stress & $25.93 \pm 6.37$ & $23.22 \pm 5.05$ & 3.853 & $<0.001$ \\
\hline
\end{tabular}

Values are presented as mean \pm standard deviation.

Table 3. Bivariate associations between occupational stress and professional quality of life ( $n=588)$

\begin{tabular}{|c|c|c|c|c|c|c|c|c|c|c|c|}
\hline Variable & 1 & 2 & 3 & 4 & 5 & 6 & 7 & 8 & 9 & 10 & 11 \\
\hline Physical environment & 1 & - & - & - & - & - & - & - & - & - & - \\
\hline Job demand & $0.360^{* *}$ & 1 & - & - & - & - & - & - & - & - & - \\
\hline Degree of autonomy & 0.031 & $-0.161^{\star \star}$ & 1 & - & - & - & - & - & - & - & - \\
\hline Relationship conflict & $0.126^{\star \star}$ & $0.244^{\star \star}$ & $0.257^{\star \star}$ & 1 & - & - & - & - & - & - & - \\
\hline Job instability & $0.323^{\star \star}$ & $0.326^{* *}$ & 0.010 & $0.170^{\star \star}$ & 1 & - & - & - & - & - & - \\
\hline Organizational system & $0.283^{* *}$ & $0.337^{* *}$ & $0.281^{\star *}$ & $0.468^{\star *}$ & $0.368^{* *}$ & 1 & - & - & - & - & - \\
\hline Lack of reward & $0.233^{\star *}$ & $0.299^{\star *}$ & $0.302^{\star \star}$ & $0.474^{\star \star}$ & $0.268^{* \star}$ & $0.572^{\star \star}$ & 1 & - & - & - & - \\
\hline Occupational climate & $0.172^{\star \star}$ & $0.226^{* *}$ & $0.214^{\star *}$ & $0.466^{\star *}$ & $0.250^{* *}$ & $0.532^{\star *}$ & $0.486^{\star *}$ & 1 & - & - & - \\
\hline Compassion satisfaction & $-0.188^{\star \star}$ & $-0.171^{\star \star}$ & $-0.192^{\star \star}$ & $-0.282^{\star \star}$ & $-0.197^{\star \star}$ & $-0.296^{\star \star}$ & $-0.496^{\star \star}$ & $-0.298^{\star \star}$ & 1 & - & - \\
\hline Burnout & $0.316^{\star \star}$ & $0.405^{\star \star}$ & $0.081^{*}$ & $0.369^{* *}$ & $0.322^{\star *}$ & $0.404^{\star *}$ & $0.452^{\star \star}$ & $0.379^{* \star}$ & $-0.612^{\star \star}$ & 1 & - \\
\hline Secondary traumatic stress & $0.307^{\star *}$ & $0.243^{* \star}$ & -0.033 & $0.181^{* *}$ & $0.241^{\star *}$ & $0.249^{\star \star}$ & $0.231^{\star *}$ & $0.205^{\star \star}$ & $-0.249^{\star *}$ & $0.637^{\star \star}$ & 1 \\
\hline
\end{tabular}

1, physical environment; 2, job demand; 3 , degree of autonomy; 4, relationship conflict; 5 , job instability; 6 , organizational system; 7 , lack of reward; 8, occupational climate; 9 , compassion satisfaction; 10 , burnout; 11 , secondary traumatic stress; - , not available. ${ }^{*} \mathrm{p}<0.05,{ }^{* *} p<0.01$. 
degree of autonomy $(\mathrm{r}=-0.192, \mathrm{p}<0.01)$, relationship conflict $(\mathrm{r}=-0.282, \mathrm{p}<0.01)$, job instability $(\mathrm{r}=-0.197$, $\mathrm{p}<0.01)$, organizational system $(\mathrm{r}=-0.296, \mathrm{p}<0.01)$, lack of reward $(\mathrm{r}=-0.496, \mathrm{p}<0.01)$, and occupational climate $(\mathrm{r}=-0.298, \mathrm{p}<0.01)$. Burnout showed a positive correlation with lack of reward $(r=0.452, p<0.01)$, job demand $(\mathrm{r}=0.405 \mathrm{p}<0.01)$, and organizational system $(\mathrm{r}=0.404$, $\mathrm{p}<0.01$ ). Secondary traumatic stress showed a positive correlation with occupational stress subfactors such as physical environment $(r=0.307, p<0.01)$, job demand $(\mathrm{r}=0.243, \mathrm{p}<0.01)$, relationship conflict $(\mathrm{r}=0.181, \mathrm{p}<0.01)$, job instability $(\mathrm{r}=0.241, \mathrm{p}<0.01)$, organizational system $(r=0.249, p<0.01)$, lack of reward $(r=0.231, p<0.01)$, and occupational climate $(\mathrm{r}=0.205, \mathrm{p}<0.01)$ (Table 3$)$.

\section{Occupational stress factors affecting compassion satisfaction}

The occupational stress factor that affected compassion satisfaction with statistical significance was lack of reward $(\beta=-0.155, \mathrm{p}<0.001)$. The explanatory variance of the final regression model was $25.1 \%$ (Table 4 ).

\section{Occupational stress factors affecting burnout}

The occupational stress factors that affected burnout with statistical significance included physical environment $(\beta=0.028, p<0.01)$, job demand $(\beta=0.042, p<0.001)$, relationship conflict $(\beta=0.033, p<0.01)$, job instability $(\beta=0.016, p<0.01)$, lack of reward $(\beta=0.051, p<0.001)$, and occupational climate $(\beta=0.024, p<0.01)$. The explanatory variable of the final regression model was $33.8 \%$ (Table 5).

\section{Occupational stress factors affecting secondary traumatic stress}

The occupational stress factors that affected secondary traumatic stress with statistical significance included physical environment $(\beta=0.063, p<0.001)$ and job instability $(\beta=0.020, p<0.05)$. The explanatory variable of the final regression model was $14.0 \%$ (Table 6 ).

Table 4. Occupational stress factors affecting compassion satisfaction $(n=588)$

\begin{tabular}{|c|c|c|c|c|c|c|c|}
\hline Model & $\beta$ & Standardized $\beta$ & $\mathrm{t}$ & $p$-value & Adjusted R Square & $\mathrm{F}$ & $p$-value \\
\hline (Constant) & 42.257 & & 37.082 & $<0.001$ & 0.251 & 25.593 & $<0.001$ \\
\hline Physical environment & -0.024 & -0.067 & -1.693 & 0.091 & & & \\
\hline Job demand & -0.001 & -0.003 & -0.069 & 0.945 & & & \\
\hline Insufficient job control & -0.024 & -0.051 & -1.270 & 0.205 & & & \\
\hline Interpersonal conflict & -0.018 & -0.044 & -1.006 & 0.315 & & & \\
\hline Job insecurity & -0.014 & -0.057 & -1.409 & 0.159 & & & \\
\hline Organizational system & 0.023 & 0.060 & 1.191 & 0.234 & & & \\
\hline Lack of reward & -0.155 & -0.431 & -9.075 & $<0.001$ & & & \\
\hline Occupational climate & -0.019 & -0.062 & -1.385 & 0.167 & & & \\
\hline
\end{tabular}

Table 5. Occupational stress factors affecting burnout $(n=588)$

\begin{tabular}{lrrrrrrr}
\hline \multicolumn{1}{c}{ Model } & \multicolumn{1}{c}{$\boldsymbol{\beta}$} & Standardized $\boldsymbol{\beta}$ & \multicolumn{1}{c}{$\mathrm{t}$} & $\mathrm{p}$-value & Adjusted R Square & $\mathrm{F}$ & $\mathrm{p}$-value \\
\hline (Constant) & 16.602 & & 23.202 & $<0.001$ & 0.338 & 38.385 & $<0.001$ \\
Physical environment & 0.028 & 0.120 & 3.201 & 0.001 & & \\
Job demand & 0.042 & 0.194 & 4.833 & $<0.001$ & & \\
\hline Insufficient job control & -0.007 & -0.022 & -0.588 & 0.557 & & \\
Interpersonal conflict & 0.033 & 0.126 & 3.054 & 0.002 & & \\
Job insecurity & 0.016 & 0.102 & 2.683 & 0.008 & & \\
Organizational system & 0.008 & 0.031 & 0.664 & 0.507 & & \\
Lack of reward & 0.051 & 0.212 & 4.750 & $<0.001$ & & \\
Occupational climate & 0.024 & 0.115 & 2.723 & 0.007 & & \\
\hline
\end{tabular}


Woo-Jeong Kim, et al. Occupational Stress and QOL in Mental Health Center

Table 6. Occupational stress factors affecting secondary traumatic stress $(n=588)$

\begin{tabular}{lccccccc}
\hline \multicolumn{1}{c}{ Model } & $\boldsymbol{\beta}$ & Standardized $\beta$ & $\mathrm{t}$ & $\mathrm{p}$-value & Adjusted R Square & $\mathrm{F}$ & $\mathrm{p}$-value \\
\hline (Constant) & 15.447 & & 17.936 & $<0.001$ & 0.140 & 14.617 & $<0.001$ \\
Physical environment & 0.063 & 0.206 & 4.829 & $<0.001$ & & \\
\hline Job demand & 0.023 & 0.082 & 1.876 & 0.061 & & \\
Interpersonal conflict & 0.016 & 0.045 & 0.971 & 0.332 & & \\
Job insecurity & 0.020 & 0.094 & 2.185 & 0.029 & & \\
Organizational system & 0.015 & 0.043 & 0.820 & 0.412 & & \\
Lack of reward & 0.019 & 0.061 & 1.209 & 0.227 & & \\
Occupational climate & 0.015 & 0.054 & 1.120 & 0.263 & & \\
\hline
\end{tabular}

\section{DISCUSSION}

The purpose of this study was to investigate the overall status of occupational stress and professional quality of life among mental health welfare center workers, and to examine the effects of occupational stress on compassion satisfaction, burnout, and secondary traumatic stress.

Among 588 subjects, 91 (15.5\%) were found to be in the occupational stress high risk group, who had lower compassion satisfaction compared to the occupational stress low risk group and experienced burnout as well as secondary traumatic stress. This is consistent with the previous finding by Hamaideh [19] that the higher the occupational stress of mental health workers, the lower the quality of life. Due to the nature of the work, mental health welfare center workers face a lot of job-related stress as they deal with patients. In addition, they are at a high risk to be in a vulnerable environment for mental health due to emotional labor [20]. These factors appear to have a negative impact on the professional inner value and quality of life.

In addition, there was a strong relationship between occupational stress, compassion satisfaction, burnout and secondary traumatic stress. In a previous study, Lloyd et al. [21] reported that social workers suffer from high levels of occupational stress and thereby experience burnout. Badger et al. [22] reported that 1) occupational stress is an important predictor of secondary traumatic stress in social workers, 2) emotional depletion occurs due to high occupational stress and 3) the ability to properly classify emotions decreases. Horowitz et al. [23] reported that higher occupational stress results in lower compassion satisfaction and higher compassion fatigue. However, not many studies on the correlation between these factors have been conducted so far. Therefore, fur- ther research on this is needed, and measures to reduce occupational stress and improve quality of life of mental health welfare center workers should be implemented.

Among the occupational stress factors in mental health welfare center workers, the lack of reward had a significant effect on compassion satisfaction in this study. In a previous study, Painter et al. [24] reported that among the occupational stress factors in occupational therapists, inadequate compensation has the biggest impact on the quality of life, indicating that inadequate compensation that is too low compared to therapeutic responsibility consequently plays a major role as a negative effect on job satisfaction. Hofmans et al. [25] reported that the level of stress in workers varies depending on the level of compensation. In general, rewards can be divided into external rewards and internal rewards. External rewards are defined as rewards from the external environment, such as money, goods, reputation, status or selfassessment [26]. Internal rewards, on the other hand, are rewards to oneself as a result of one's actions [27]. Therefore, in future, it is required to provide appropriate external rewards by improving the salary, welfare, and employment stability of workers in mental health welfare centers, and to provide internal rewards such as a sense of belonging and skill development through employee training and workshops.

Among the subfactors of occupational stress, burnout was higher when there were more job requirements and inadequate compensation or unfair treatment. Also, the higher the scores for physical environment, relationship conflict, occupational climate, and job instability, the higher the burnout. In a previous study, Ogresta et al. [28] reported that lack of reward, physical environment, and occupational climate factors affect the degree of burnout in mental health service workers. Xie et al. [29] reported 
similar findings in a study showing that, among the factors that affect burnout and induce emotional fatigue, job instability, relationship conflict and lack of reward had an effect on burnout. These findings are consistent with the results of the study by Acker [30] who reported that high job turnover among young workers with low grades, frequent shifts, and low wages was due to excessive job demand, lack of reward, and job instability. In general, these factors seemed to be major causes of increasing occupational stress and increased risk of burnout in mental health welfare center workers in this study. Therefore, it is necessary to find ways to help mental health welfare center workers to maintain and build up their careers through policy support, and to support the use of leave system and flexible management of time and attendance system as needed. At present, mental health promotion projects have been repeatedly supported without considering budget, manpower shortages, regional demographics and mental health problems [31]. In future, it is necessary to identify the trends in national health indicators in order to provide the financial support that can cover the socio-economic costs, and to improve the support system with attention to improving the working environment. However, in this study, the degree of autonomy and organizational system was not found to affect burnout. It is possible that the measured values used in the study were incompatible due to the varied occupations and working hours of the subjects in this study. In a previous study, Lee et al. [32] reported that burnout was affected by lack of reward, relationship conflict, degree of autonomy, organizational system, job demand, job instability and occupational climate, in order, while Maslach et al. [11] reported that burnout increased when there was little authority to determine treatment and short break times followed by lack of autonomy. Therefore, future studies should discuss ways to improve the operation of objective indicators including quantitative and qualitative measures such as occupations and working hours.

Among the subfactors of occupational stress, physical environment and job instability were found to significantly affect secondary traumatic stress. In a previous study, Yang and Kim [33] reported that the risk of experiencing violence was the highest among the factors affecting secondary traumatic stress in female social workers. According to Bride [34], secondary traumatic stress was higher when there was higher probability of accidents or assault and verbal abuse from service recipients, greater physical burden and long hours of work in an uncomfortable posture. In addition, secondary traumatic stress scores also increased when the future seemed uncertain due to unstable circumstances at work or when there was a negative change expected at work. Therefore, it is a matter of urgency to improve the situation so that the mental health welfare center workers can work in a safe environment.

Kim et al. [35] noted that it is important to provide mental health services to mental health professionals to increase the protective factors of mental health work itself and to cope with occupational stress appropriately. Therefore, it is necessary to periodically identify major mental health indicators such as occupational stress and quality of life in mental health welfare center workers, and establish a linkage system to receive appropriate counseling and treatment if they are identified as a highrisk group for occupational stress.

The limitations of this study are: first, the study did not use random sampling and the respondents were localized to a specific area. Therefore, there is a limitation in generalizing the results of this study. Second, there was a cross-sectional evaluation of occupational stress and quality of life. Third, the risk of response bias cannot be eliminated because the data were collected and measured using self-administered questionnaires subjectively completed by respondents. Fourth, It may not be appropriate to assess secondary traumatic stress, as not all mental health welfare center workers face-to-face with trauma patients. Fifth, the factors related to mental health of mental health welfare center workers may include various variables in addition to occupational stress and quality of life, and empirical research covering various factors is needed.

Nevertheless, this study is meaningful in that it evaluates occupational stress and quality of life in mental health welfare center workers. Based on this, it is necessary to continue to pay attention to the policy suggestions and management directions for improving the quality of life of mental health workers in the future.

\section{CONFLICTS OF INTEREST}

The authors have nothing to disclose. 


\section{ORCID}

\author{
Woo-Jeong Kim \\ https://orcid.org/0000-0002-8288-3470 \\ Kwang-Hun Lee \\ https://orcid.org/0000-0003-4531-8015 \\ Bo-Hyun Yoon \\ https://orcid.org/0000-0002-3882-7930 \\ Jong-Hun Lee \\ https://orcid.org/0000-0002-3581-5029 \\ Moon-Doo Kim \\ https://orcid.org/0000-0002-6441-630X \\ Young-Eun Jung \\ https://orcid.org/0000-0001-7608-0009 \\ Min-Jung Soh \\ https://orcid.org/0000-0003-1033-9449 \\ Sang-Yeol Lee \\ https://orcid.org/0000-0003-1828-9992
}

\section{REFERENCES}

1. Choi SC, Lee JS, Sim SY, Lee JH, Park JH. The effect of job stress and depression on job satisfaction among workers in small and medium sized enterprises. J Converg Inf Technol 2017;7:1-9.

2. Lim HJ, Gang MH, Oh KO. Nursing activity, job stress, and job satisfaction of nurses in community mental health facilities. J Digit Converg 2013;11:507-13.

3. Caplan RD. Person-environment fit theory and organizations: commensurate dimensions, time perspectives, and mechanisms. J Vocat Behav 1987;31:248-67.

4. Figley CR. Compassion fatigue: psychotherapists' chronic lack of self care. J Clin Psychol 2002;58:1433-41.

5. Bride BE, Radey M, Figley CR. Measuring compassion fatigue. Clin Soc Work J 2007;35:155-63.

6 . Radey M, Figley CR. The social psychology of compassion. Clin Soc Work J 2007;35:207-14.

7. Slocum-Gori S, Hemsworth D, Chan WW, Carson A, Kazanjian A. Understanding compassion satisfaction, compassion fatigue and burnout: a survey of the hospice palliative care workforce. Palliat Med 2013;27:172-8.

8. Adams RE, Boscarino JA, Figley CR. Compassion fatigue and psychological distress among social workers: a validation study. Am J Orthopsychiatry 2006;76:103-8.

9. Stamm B. The concise manual for the professional quality of life scale. Pocatello: THE ProQOL; 2010.

10. Bride BE, Robinson MM, Yegidis B, Figley CR. Development and validation of the secondary traumatic stress scale. Res Soc Work Pract 2004;14:27-35.

11. Maslach C, Schaufeli WB, Leiter MP. Job burnout. Annu Rev Psychol 2001;52:397-422.
12. Rothmann S. Job satisfaction, occupational stress, burnout and work engagement as components of work-related wellbeing. SA J Ind Psychol 2008;34:11-6.

13. Lee MS. Burnout process model of social workers: analysis of the paths from the job-related stressors, job-stress and professional self-efficacy to burnout. Korean J Soc Welf 2004;56:5-34.

14. Sung MH, Yoon HO, Lee HJ. A study on relationship between job stress, burnout experience and job satisfaction of nurses. Korean J Occup Health Nurs 2007;16:147-57.

15. Lee HK, Jung JY. Study of job stress, burnout, and compassion satisfaction of occupational therapists in rehabilitation hospitals. J Spec Educ Rehabil Sci 2014;53:177-92.

16. Chang SJ, Koh SB, Kang D, Kim SA, Kang MG, Lee CG, et al. Developing an occupational stress scale for Korean employees. Ann Occup Environ Med 2005;17:297-317.

17. Kim JK, Kim JE, Moon DH. Effect of occupational stress and sleep quality on depression among male immigrant workers manufacturing industry, Korea. J Korean Soc Occup Environ Hyg 2012;22:244-56.

18. Joo HS, Cho YW, Ahn HN. Validation of the Korean version of Professional Quality of Life Scale 5 (K-ProQOL 5) for mental health professional. Cognit Behav Ther Korea 2016;16:269-98.

19. Hamaideh SH. Occupational stress, social support, and quality of life among Jordanian mental health nurses. Issues Ment Health Nurs 2011;33:15-23.

20. Chong HS, Ko SH, Kim JY. Impact of empathy ability and gratitude disposition on job satisfaction in psychiatric nurses. J Digit Converg 2017; 15:395-405.

21. Lloyd C, King R, Chenoweth L. Social work, stress and burnout: a review. J Ment Health 2002;11:255-65.

22. Badger K, Royse D, Craig C. Hospital social workers and indirect trauma exposure: an exploratory study of contributing factors. Health Soc Work 2008;33:63-71.

23. Horowitz SM, Blackburn RT, Edington DW, Kloss DM. Association between job stress and perceived quality of life. J Am Coll Health 1988;37:29-35.

24. Painter J, Akroyd D, Wilson S, Figuers C. The predictive value of selected job rewards on occupational therapists' job satisfaction in ambulatory care settings. Occup Ther Health Care 1995;9:21-37.

25. Hofmans J, De Gieter S, Pepermans R. Individual differences in the relationship between satisfaction with job rewards and job satisfaction. J Vocat Behav 2013;82:1-9.

26. Folger R, Rosenfield D, Hays RP. Equity and intrinsic motivation: the role of choice. J Pers Soc Psychol 1978;36:55764.

27. Cast AD, Burke PJ. A theory of self-esteem. Soc Forc 2002;80:1041-68.

28. Ogresta J, Rusac S, Zorec L. Relation between burnout syndrome and job satisfaction among mental health workers. Croat Med J 2008;49:364-74.

29. Xie Z, Wang A, Chen B. Nurse burnout and its association with occupational stress in a cross-sectional study in 
Shanghai. J Adv Nurs 2011;67:1537-46.

30. Acker GM. The impact of clients' mental illness on social workers' job satisfaction and burnout. Health Soc Work 1999;24:112-9.

31. Lee SY. Future directions and issues of mental health policies in Korea. Health Welf Policy Forum 2012;187:68-77.

32. Lee HK, Jung JY. Factors of job stress influencing burnout and compassion satisfaction in occupational therapist. J Spec Educ Rehabil Sci 2016;55:233-45.
33. Yang JB, Kim JY. Factors on secondary traumatic stress of women public social welfare specialists. Korean Soc Well 2015;10:123-33.

34. Bride BE. Prevalence of secondary traumatic stress among social workers. Soc Work 2007;52:63-70.

35. Kim KH, Park JR. The emotional intelligence of psychiatric patients on ability model: a convergent using of performance test and self-report test. J Korea Converg Soc 2017;8:35-42. 